\title{
Mural Hunter: una app de catalogación y diálogo en torno al patrimonio artístico urbano
}

\author{
Iñaki Navarro Neri | Dpto. Didácticas Específicas, U. de Zaragoza \\ URL de la contribución <www.iaph.es/revistaph/index.php/revistaph/article/view/4871>
}

¿Son los ciudadanos y ciudadanas quienes deciden qué elementos artísticos de su entorno más próximo forman parte de la identidad del lugar en el que viven? O, por el contrario, ¿es el propio espacio quien con el paso de los años va sembrando el sentimiento de pertenencia y de identificación en sus habitantes? Si asumimos como propios monumentos, edificios, plazas e incluso calles ¿por qué no hacer lo mismo con el patrimonio artístico urbano?

Desde la Convención de Faro en el año 2005 donde se apuntaba que la creación de contenidos digitales no debía frenar las actividades de conservación y preservación del patrimonio existente (Convenio Marco 2005, art. 14d), es precisamente la preservación digital del patrimonio (digitalización de colecciones, catalogaciones, etc.) quien se ha erigido como un espacio potencial para el surgimiento de procesos educomunicativos vinculados al patrimonio.

El uso de las TIC en educación patrimonial ha permitido sin duda un diálogo más ágil y rico entre sujetos y objetos permitiendo en definitiva que los sujetos construyan y gestionen su propio conocimiento. Socializar el arte mural urbano permite que esa conexión sujeto-objeto se base en la participación directa y activa de la ciudadanía en el patrimonio más allá de perspectivas economicistas (Cuenca López 2016).

El uso de las TIC de forma generalizada cuenta ya con un recorrido cercano a los 25 años lo que ha permitido a los usuarios y usuarias ir dejando atrás un rol pasivo como meros consumidores para llegar a desempeñar roles más activos e incluso transformadores. Es decir, el paso de las TIC a las TAC y finalmente a las TEP: de las tecnologías de la Información y la educación, a las tecnologías para el aprendizaje y el conocimiento para llegar a las tecnologías para el empoderamiento y la participación (Cabero 2015). Este empoderamiento en la red debe transformar al ciudadano digital en alguien crítico que pueda aspirar a un activismo digital en pos de la igualdad, la justicia social y la defensa del patrimonio (Magro 2015). Es decir, hacer de los espacios digitales lugares para una convivencia transformadora, reflexiva y crítica (Correa et ál. 2018, 42).

Mientras el arte mural urbano goza cada vez de una mayor aceptación institucional, siempre que la temática sea sugerida desde algún organismo, como por ejemplo a través de concursos organizados por ayuntamientos para la "transformación" de determinados espacios urbanos, en los últimos meses hemos visto cómo muchos de estos murales han sido atacados (por ejemplo el caso de Madrid) o directamente retirados (como en Pamplona). Esto demuestra la necesidad de una educación patrimonial basada en el respeto y la necesidad de diálogo y debate en torno a cualquier forma de expresión artística.

Su carácter crítico y preferentemente efímero hace del patrimonio artístico urbano un elemento de difícil raigambre en el imaginario local pero no por ello debe ser descartado como un punto de encuentro para el diálogo y el aprendizaje en torno al patrimonio. Por ello, desde la Universidad de Zaragoza, el proyecto de ciencia ciudadana CIVITAS 2.0: espacio abierto para la educación patrimonial, diseñó Mural Hunter, una app para la catalogación, preservación digital e interpretación del arte urbano mural (Rivero y Gil-Díaz 2016, 2018).

El proyecto se plantea como una iniciativa de ciencia ciudadana en tanto que son los propios usuarios y usuarias, a los y las que no se requiere una formación especiali- 


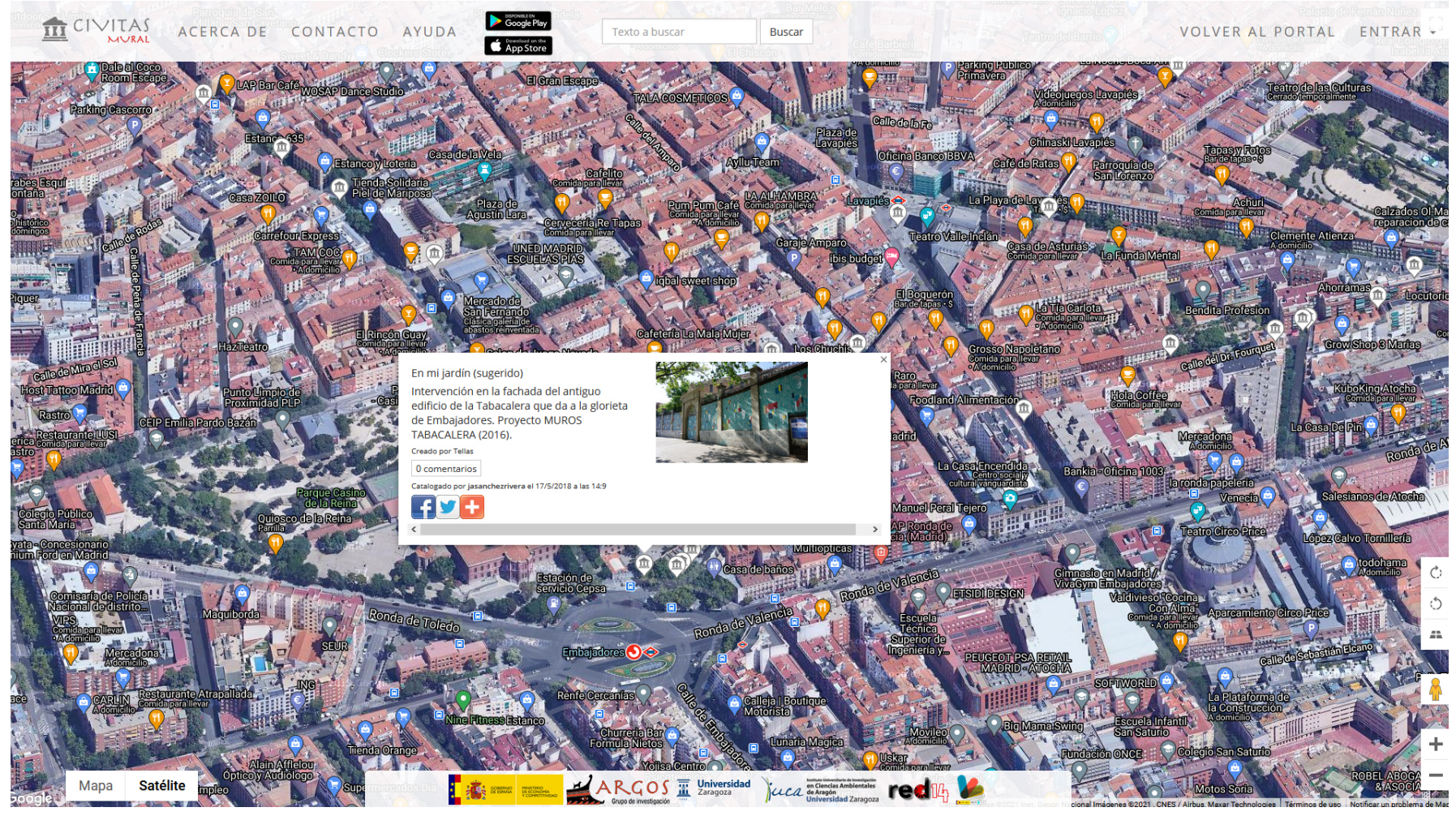

http://civitas.unizar.es/mural

zada previa, quienes geoposicionan sus fotografías de murales de arte urbano desde su ordenador o dispositivo móvil (bien utilizando la aplicación Mural Hunter aprovechando la ubicación automática del dispositivo o desde la web general a través de su sección "mural"), proporcionando datos para su catalogación, así como comentarios personales.

Esta app permite a los usuarios y usuarias desde cualquier punto del planeta compartir la geolocalización de cualquier expresión de arte urbano que les haya llamado la atención. Tras su geolocalización, el usuario o usuaria debe adjuntar la foto correspondiente y puede añadir más información como: sugerir un título, añadir un comentario o señalar la autoría en caso de que sea posible. Esto nos permite hablar de una app nacida para establecer puentes entre personas de cualquier parte del mundo que quieren poner en valor el patrimonio urbano local, pero sobre todo, nos permite hablar de una aplicación capaz de generar un potente archivo fotográfico de expresiones artísticas efímeras sin repercutir en la propia identidad de las obras. Además, al permitir subir varias imágenes de la misma obra, se facilita el seguimiento de la evolución de la misma, desde su creación hasta, si es el caso, su desaparición o sustitución por una nueva obra sobre el mismo muro, perviviendo la obra desaparecida en el medio digital.

Tras tres años de trayectoria, la app cuenta con 235 miembros activos que comparten sus imágenes y la localización de las mismas a lo largo de todo el planeta. Se trata de una aplicación en continuo crecimiento que también ha dado el salto a Facebook posibilitando el surgimiento de una cibercomunidad patrimonial (Rivero, Navarro-Neri y Aso 2020) de más de 200 personas.

A través de este proyecto se pretende ir confeccionando un catálogo de arte mural a nivel mundial y, al hacerlo 
mediante una iniciativa colaborativa de ciencia ciudadana con un elevado grado interactividad creativa, se pretende también potenciar la creación de una comunidad patrimonial unida por el arte mural urbano de carácter transnacional, fomentando la ciudadanía se active en la defensa del patrimonio y potenciando un proceso de patrimonialización del arte mural urbano.

En definitiva, la consolidación de una app como Mural Hunter ha permitido el surgimiento de una cibercomunidad patrimonial dinámica y siempre abierta a sumar nuevos activos en un grupo de personas unidas a través de la red por el interés y la defensa del patrimonio. Un grupo de personas que comparten y generan conocimiento y debate sobre el arte mural urbano dejando atrás el rol de consumidores pasivos.

\section{BIBLIOGRAFÍA}

- Cabero Almenara J. y Barroso Osuna J. (coord.) (2015) Nuevos retos en tecnología educativa. España: Síntesis

- Consejo de Europa (2005) Convenio Marco del Consejo de Europa sobre el valor del patrimonio cultural para la sociedad. Faro, 27 de octubre de 2005. Serie de Tratados del Consejo de Europa, n. ${ }^{\circ}$ 199. Disponible en: https://rm.coe.int/16806a18d3 [Consulta: 15/03/2021]

- Correa J.M., Aberasturi Apraiz E., Gutiérrez-Cabello A. y Guerra R. (2018) Usos críticos de las tecnologías digitales para el aprendizaje dentro y fuera de los contextos institucionales de formación. En: Arancibia Martini. H., Castillo Armijo P. y Saldaá Fernández. J. (coord.) Innovación Educativa: perspectivas y desafíos. Chile: Universidad de Valparaíso

- Cuenca López J.M. (2016) Escuela, patrimonio y sociedad. La socialización del patrimonio. Revista UNES. Universidad, Escuela Y Sociedad, n. ${ }^{\circ}$ 1, pp. 22-41. Disponible en: https:// revistaseug.ugr.es/index.php/revistaunes/article/view/12148 [Consulta: 15/03/2021]

- Magro, C. (2015) Coches voladores, tecnologías poéticas y cambio educativo. co.labora.red, 27 de noviembre de 2015. Disponible en: https://carlosmagro.wordpress.com/2015/11/27/ coches-voladores-tecnologias-poeticas-y-cambio-educativo/ [Consulta: 16/03/2021]

- Rivero, P. y Gil-Diez, I. (2016) Ciencia ciudadana, arqueología y educación patrimonial. En: López Facal, R. (ed.) Libro de Actas del Simposio Ciencias sociales, educación y futuro. Investigaciones en didáctica de las ciencias sociales. Santiago de Compostela: Universidad de Santiago de Compostela, pp. 578-585

- Rivero, P. y Gil-Díez, I. (2018) Una propuesta de ciencia ciudadana para la educación patrimonial: civitas. En: López Torres, E., García Ruíz C.R. y Sánchez Agustí, M (ed.) Buscando formas de enseñar: investigar para innovar en didáctica de las ciencias sociales. España: Universidad de Valladolid

- Rivero, P., Navarro-Neri, I. y Aso, B. (2020) Educommunication Web 2.0 for Heritage: A View From Spanish Museums. En: Delgado-Algarra, J. y Cuenca-López, J.M. (ed.) Handbook of Research on Citizenship and Heritage Education. s.I.: IGI Global, pp. 450-471. Disponible en: https:// www.igi-global.com/chapter/educommunication-web-20-forheritage/246795 [Consulta: 15/3/2021] 